\title{
Sie wächst und wächst und wächst - Komplexität in der IT
}

IT-Landschaften haben die Neigung, zu wachsen. Dabei werden sie zwangsläufig gleichzeitig komplexer. Wer hier nicht gezielt strategisch handelt, steht irgendwann vor großen Schwierigkeiten. Analoges gilt für IT-Projekte im großen Maßstab. Auch hier ist es wichtig, die Komplexität auf das notwendige Maß zu reduzieren.

Die zunehmende Vernetzung von Unternehmen mit Zulieferern und Kunden - auch über Ländergrenzen hinweg - trägt dazu bei, dass diese Aufgabe in Zukunft nicht leichter werden wird. Falsch wäre es, zu glauben, man könne die Komplexität loswerden. Vielmehr kommt es darauf an, dass man lernt, mit

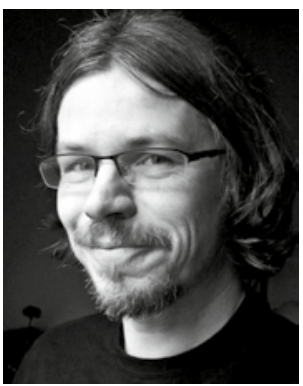

Peter Pagel

Chefredakteur ihr zu leben, sich mit ihr arrangiert. So ist es möglich, das Leiden an der Komplexität zu lindern. Komplexitäts-Management wird zu einer immer wichtigeren Teilaufgabe in der IT.

Hinzu kommt: Immer mehr Unternehmen arbeiten seit Langem mit IT. Dieses digitale Erbe (Legacy) kann oft nicht einfach ersetzt werden, Banken und Versicherungen sind mit dieser Herausforderung wohl vertraut. Welche Ansätze es gibt, wo Herausforderungen liegen - etwa auch bezüglich der Anforderungen an neue Mitarbeiter - sind Themen dieser Ausgabe.

Herzlichst, Ihr

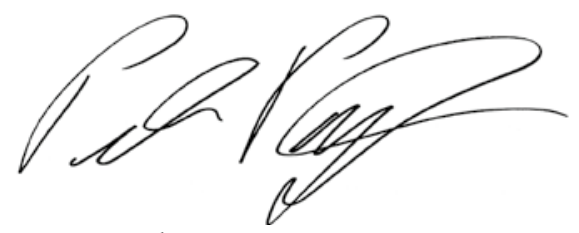

Peter Pagel 